\title{
EFFECT OF AMBIENT AIR CONDITIONS ON LOW FREQUENCY NEGATIVE CAPACITANCE OF NC-TIO $/ 23$ P3T HETEROJUNCTION SOLAR CELLS
}

\begin{abstract}
H. Al-Dmour
Department of Physics, Faculty of Science, Mu’tah University, Mu’tah, Jordan

Received 2014-02-26; Revised 2014-04-08; Accepted 2014-05-28

ABSTRACT

We report the negative capacitance of nanocrystalline titanium dioxide/poly (3-hexyl thiophene), nc- $\mathrm{TiO}_{2} / \mathrm{P} 3 \mathrm{HT}$, heterojunction solar cells. In air, low frequency negative capacitance has been observed under forward bias associated with high values of conductance. Interestingly, the negative capacitance disappear when the device was placed in vacuum chamber. These results are attributed to affect the ambient conditions on the charge carrier concentration in materials used to fabricated solar cells and increase the bulk region resistance.
\end{abstract}

Keywords: Solar Cells, Admittance Techniques, Bulk Heterojunction, Ambient Conditions

\section{INTRODUCTION}

In the last decades, many researchers have used small-signal admittance techniques to identify microscopic processes in electronic devices, for example, charges recombination and generation at interfacial areas such as metal/semiconductor or semiconductor/insulator (Zaki et al., 2013; Itoj and Nakagoshi, 2014; Taylor et al., 1991; Stallinga et al., 2002). The interface and bulk region of solar cells extend only few hundred nanometer and their properties affect on the devices performance and stability (Jørgensen et al., 2008; Rahid et al., 2013). Thus, organic materials have been under intensive investigation to improve the properties of interface and bulk region. To explore the physical mechanisms at interfaces, studying capacitance characteristic of organic devices under different frequencies is a useful method to achieve that. One of these mechanisms is Negative Capacitance (NC) which appears in organic solar cells and light emitting diodes. This Phenomenon have attracted a lot of attentions. For example, according to (Zhu et al., 2009), the NC has great relation to injection carriers recombination in the active region in Organic Light Emitting Diodes (OLEDs). While in (El-Kamel et al., 2008) observed NC in hydrogendoped barium titanate films found that this behaviour is related to proton and oxygen vacancy conduction. The appearance of $\mathrm{NC}$ in signal admittance measurements indicates the processes occurred at interfaces in organic electronic device either generation of exciton (electron-hole pair) in solar cells or recombination of exciton in light emitting diode. However, the origin of negative capacitance remains controversial. In this study, we studied the negative capacitance and loss (conductance/angular) frequency versus voltage under different frequencies in air and vacuum. Comparing the results obtained, we found that the negative capacitance in $\mathrm{P} 3 \mathrm{HT} / \mathrm{nc}-\mathrm{TiO}_{2}$ solar cells depends on the ambient conditions.

\section{EXPERIMENTAL PART}

The devices studied here were fabricated on fluorinedoped, tin oxide $\left(\mathrm{SnO}_{2}: \mathrm{F}\right)$ electrodes, pre-coated with a thin, dense layer of $\mathrm{TiO}_{2}$. A nc- $-\mathrm{TiO}_{2}$ paste was then spread over the substrates using a doctor blade and cured to form the anatase phase following the procedures described in (Al-Dmour et al., 2009; Gebeyehu et al., 2001). Typically, the resulting porous, $\mathrm{nc}^{-\mathrm{TiO}_{2}}$ layer was $\sim 2 \mu \mathrm{m}$ thick. A drop of P3HT in chloroform $(15 \mathrm{mg}$ $\mathrm{mL}^{-1}$ ) was allowed to suffuse into this layer for several seconds prior to spincoating at $1000 \mathrm{rpm}$. The devices were completed by evaporating an array of $3 \mathrm{~mm}^{2}$, circular gold electrodes onto the P3HT. 
Admittance measurements were carried out over the frequency range $1 \mathrm{~Hz}$ to $1 \mathrm{MHz}$ with a signal amplitude of $100 \mathrm{mV}$ using a Solartron 1260 Frequency Response Analyzer under different bias voltages both in air and under a vacuum of $\sim 10^{-5}$ torr. The device was under forward bias condition when the negative voltage was applied on $\mathrm{SnO}_{2}$ : Fn.

\section{RESULTS}

In our previous report (Al-Dmour et al., 2011), the frequency-dependence of the loss tangent indicated the presence of two processes in air: (1) the weaker is attributed to adsorbed water molecules on the surface of the nc- $\mathrm{TiO}_{2}$; (2) the second process is believed to arise from the presence of an interfacial capacitance. That measurements were conducted under low forward bias condition where the capacitance values were in the positive region.

Figure 1a shows the capacitance-voltage characteristics of $\mathrm{P} 3 \mathrm{HT} / \mathrm{nc}-\mathrm{TiO}_{2}$ solar cells at $10 \mathrm{kHz}$ in air. The capacitance is weakly dependent on the positive biases in comparison with negative biases. It increases rapidly until it reaches a peak at $-0.95 \mathrm{~V}$, Then, the capacitance starts falling down to negative region with increase of applied voltage to $-1.65 \mathrm{~V}$. The

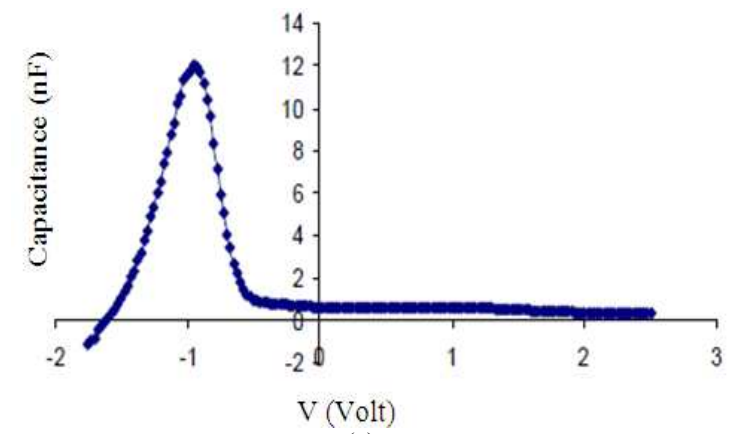

(a) measurements were also conducted on the device at lower frequencies, the $\mathrm{NC}$ is appeared at different values for $1 \mathrm{KHz}$ and $1 \mathrm{~Hz}$ (Fig. 1b and c) in air.

Figure 2 shows the characteristics of loss (conductance/angular frequency)-voltage of P3HT/nc$\mathrm{TiO}_{2}$ solar cells at different frequencies in air. The values of loss were dependent on voltage applied on the device and frequencies of the ac signal supercomposed on the device. At $10 \mathrm{KHz}$ (Fig 2a), the loss was very low under postive bias condition and then increase rapidly with increase of negative bias conditions. Simliar behaviour were obtained on the device at $1 \mathrm{Khz}$ and $1 \mathrm{~Hz}$ (Fig 2b and c). On other and, the higher values of loss were obsereved at low frequencies at $1 \mathrm{~Hz}$, the loss was around $1000 \mathrm{nF}$ while it was around $60 \mathrm{nF}$ at $1 \mathrm{KHz}$. The same measurements in the above was repeated in vacuum (Fig. 3). The $\mathrm{C}-\mathrm{V}$ characteristics of P3HT/nc$\mathrm{TiO}_{2}$ did not show any sign of negative capacitance, the values of capacitance were constant and did not change when the voltage bias scan move from negative to positive bias in vacuum. In addition to that, Fig $\mathbf{4}$ and 5 show the loss versus voltage characteristics of P3HT/nc$\mathrm{TiO}_{2}$ solar cells in vacuum. Similar to capacitance measurements in vacuum, the loss were independent on voltage bias and did not change when the voltage bias scan move from negative to positive bias.

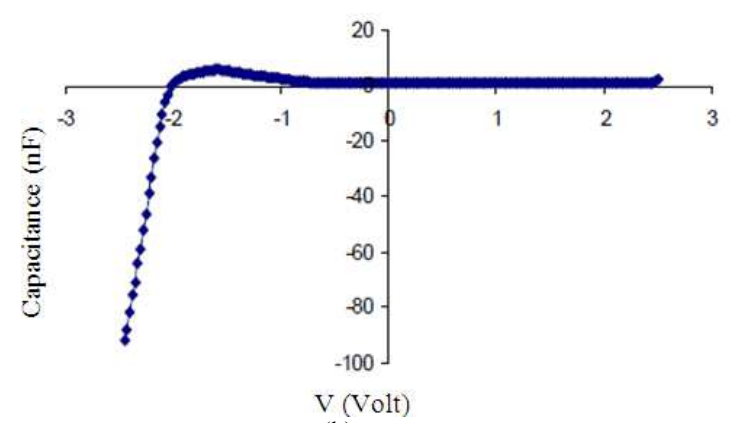

(b)

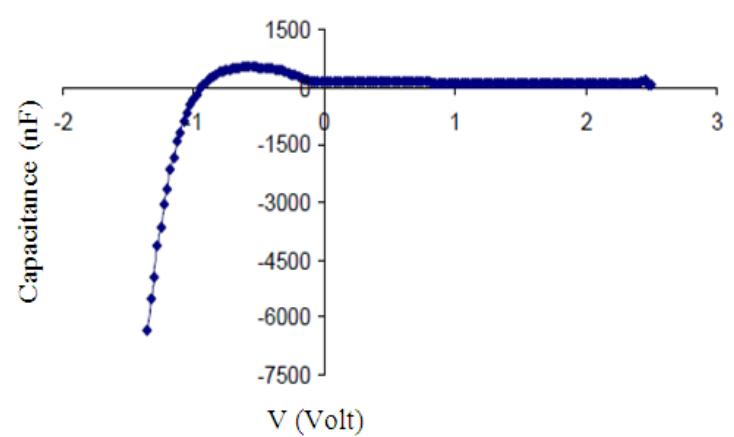

(c)

Fig. 1. Capacitance-voltage plots of nc-TiO $2 / \mathrm{P} 3 \mathrm{HT}$ solar cells in air at (a) $10 \mathrm{KHz}$ (b) $1 \mathrm{KHz}$ (c) $1 \mathrm{~Hz}$ 


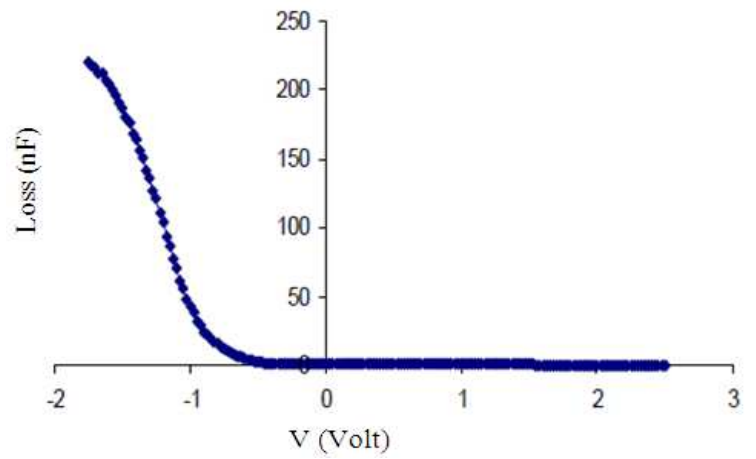

(a)

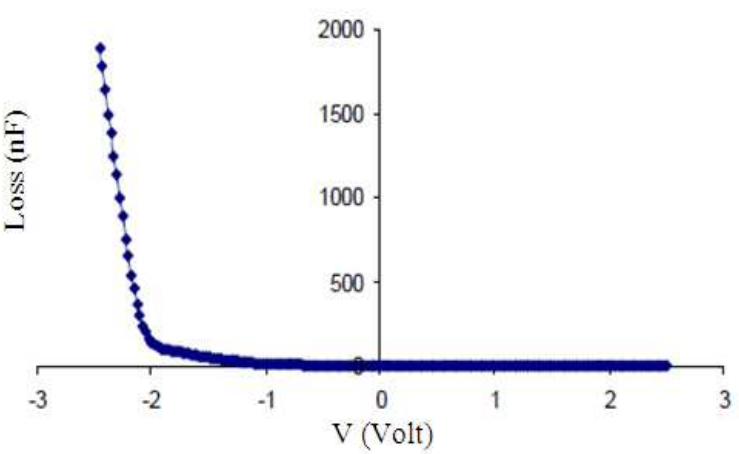

(b)

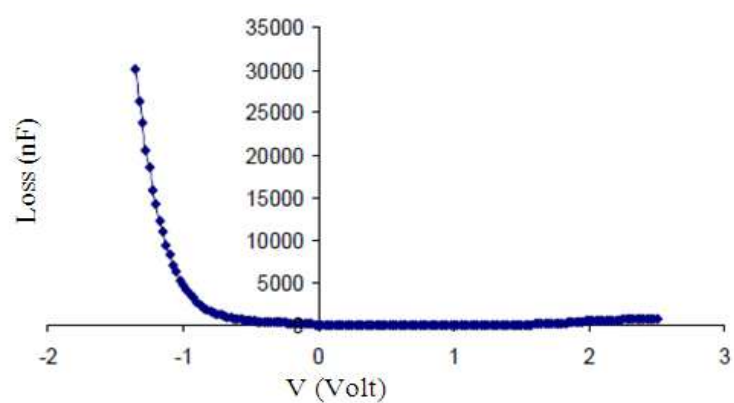

(c)

Fig. 2. Loss-voltage plots for the nc- $\mathrm{TiO}_{2} / \mathrm{P} 3 \mathrm{HT}$ solar cells measured in air at (a) $10 \mathrm{KHz}$ (b) $1 \mathrm{KHz}$ (c) $1 \mathrm{~Hz}$

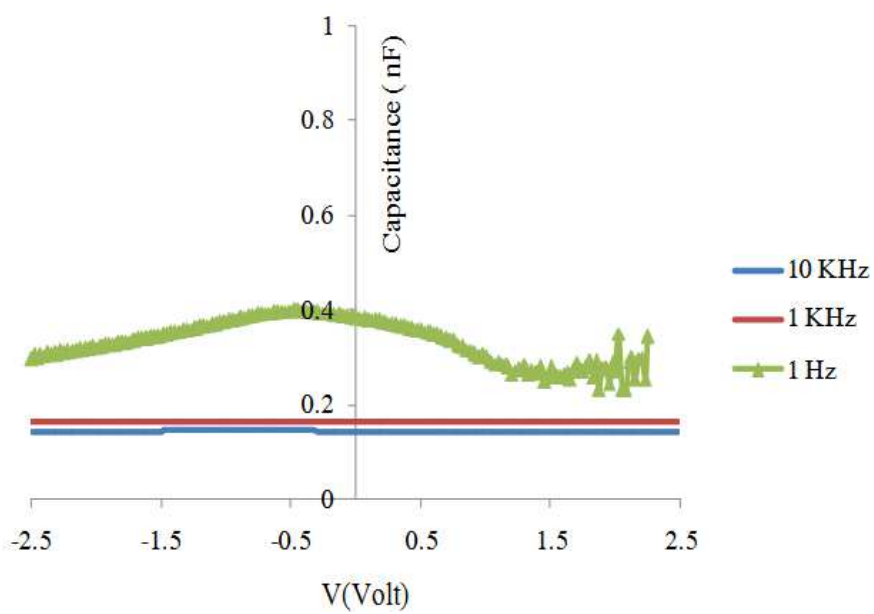

Fig. 3. Capacitance-voltage plots for the $\mathrm{nc}-\mathrm{TiO}_{2} / \mathrm{P} 3 \mathrm{HT}$ solar cells measured in vacuum at $10 \mathrm{KHz}, 1 \mathrm{KHz}$ and $1 \mathrm{~Hz}$

\section{DISCUSSION}

The results may be explained by applying capacitance characteristics of inorganic pn junctions. Basically, the total capacitance $\left(\mathrm{C}_{\mathrm{tot}}\right)$ of the solar cells is the series sum of geometrical Capacitance $\left(\mathrm{C}_{\mathrm{g}}\right)$ and depletion Capacitance $\left(\mathrm{C}_{\mathrm{d}}\right)$ given by Equation 1:

$$
\mathrm{C}_{\text {tot }}=\frac{\mathrm{C}_{\mathrm{g}} \mathrm{C}_{\mathrm{d}}}{\left(\mathrm{C}_{\mathrm{g}}+\mathrm{C}_{\mathrm{d}}\right)}
$$

Under positive biases, the capacitance $\left(C_{t o t}\right)$ in the reverse bias region is dominated by geometrical capacitance of the device in air. In this case, It is suggested that the 
resistivity in bulk is low in comparison of resistivity at interface where the width of depletion region is largely grown and shunt the depletion capacitance. The capacitance here is almost unchangeable because the majority of carriers carriers hardly follow the increase of positive voltage. On other hand, the width of depletion region in forward bias starts to decrease during applying negative bias on $\mathrm{SnO}_{2}$ : Fn electrode. That attribute the sharply arise capacitance in Fig. 1 similar to results reported by (Zang et al., 2014; Fan et al., 2001). The increase in the capacitance of device doesn't only come from the change of depletion region width. Our results shows that an addition capacitance is connected on parallel with depletion capacitance to form junction capacitance under high negative bias conditions.

This addition is known as a diffusion or chemical capacitance $\left(\mathrm{C}_{\text {diff }}\right)$ (Sero et al., 2009; Tsai et al., 2006; Lindmayer and Wringle, 1966) and comes from an accumulation of non recombine excess holes in n-type layer $\left(\mathrm{nc}-\mathrm{TiO}_{2}\right.$ thin film) and non recombine excess electrons in P-Type (P3HT). According to Equation 2 (Sero et al., 2009; Lindmayer and Wringle, 1966):

$$
\mathrm{C}_{\text {tdiff }}=\frac{\mathrm{qI}}{\mathrm{KT}}\left(\frac{\tau}{2 \omega}\right)^{\frac{1}{2}}
$$

Where:

$$
\begin{aligned}
\mathrm{I} & =\text { Forward bias current } \\
\tau & =\text { Relaxation time and } \\
\mathrm{T} & =\text { The temperature }
\end{aligned}
$$

The diffusion capacitance is affected by the frequency of applied AC voltage as shown in our results. For low frequency, more trapped charge carriers at interface can follow the ac signal because the period of the ac voltage is getting close or less than to the dielectric relaxation time of the semiconductor. That may interpret the very large capacitance enhancement at frequency of $1 \mathrm{~Hz}$ in comparison with frequency of 10 KHz. As cane been seen in Fig. 2, the loss (conductance/angular frequency) increase with decrease of frequency in the same regions of change in capacitances. It confirms the increase of passing trap charge carrier through the interface.

In the negative capaictance, we observed that It appears when The forward bias voltage increase to certain value or/and decrease of frequency. A previous study by Arsian et al. (2010) concludes that negative capacitance at low frequency in high forward bias is believed to arise from high level injection of minority charge carriers into the bulk region of the device with decreasing in the series resistance. In this study, the minority charges carries accumulated at interface between $\mathrm{P} 3 \mathrm{HT}$ and $\mathrm{nc}-\mathrm{TiO}_{2}$ plays an important role in displaying the negative capacitance (inductive behaviour). The current lags behind applied field on the device because these charge carriers are recombined by injected charges from electrodes and then hoping from interface to pass though the materials. The latter mechanism is found to require certain time before the charges follow the dc voltage signal and appear the negative capacitance. Thus, more time will be given to charges to move toward the interface and increase of the negative capacitance.

Interestingly, the negative capacitance was not observed in vacuum. That may relate to the electrical properties of materials in our solar cells (Meijer et al., 2004). The conductivity of $\mathrm{P} 3 \mathrm{HT}$ and $\mathrm{nc}-\mathrm{TiO}_{2}$ in vacuum were lower than when the devices were in air (Fig. 4 and 5).

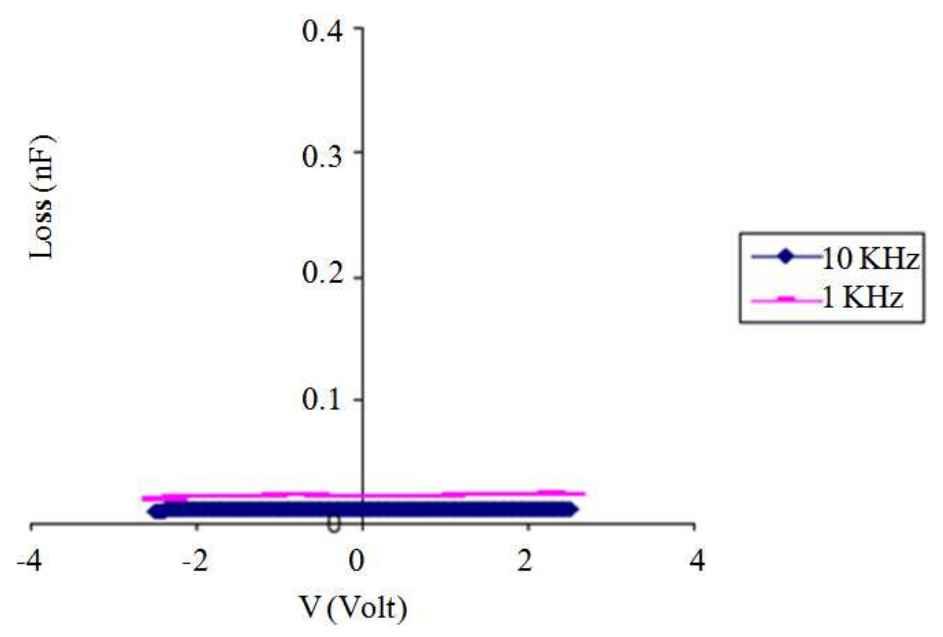

Fig. 4. Loss-voltage plots for the $\mathrm{nc}-\mathrm{TiO}_{2} / \mathrm{P} 3 \mathrm{HT}$ solar cells measured in vacuum at $10 \mathrm{KHz}, 1 \mathrm{KHz}$ 


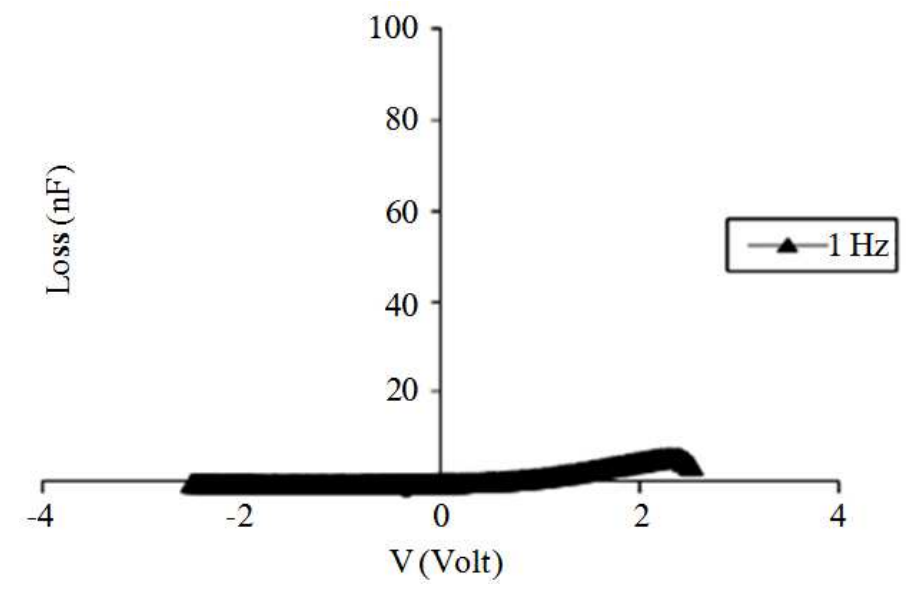

Fig. 5. Loss-voltage plot for the $\mathrm{nc}-\mathrm{TiO}_{2} / \mathrm{P} 3 \mathrm{HT}$ solar cells measured in vacuum at $1 \mathrm{~Hz}$

In the absence of oxygen, the concentration of charge carriers at interface were decreased which led to increase the shunt and bulk region resistance. This is in agreement with our published results in (Al-Dmour and Taylor, 2009) show the dependent of open circuit voltage on the ambient condition. By removing air form the vacuum charmer, the device present neither capacitor nor inductive but it only behaves as insulator. Therefore, the disappearance of negative capacitance observed in this study and decrease in the perfomance of solar cells in vacuum migh be caused by the same thing. According to that, the presence of negative capacitance indicates a good solar cells.

\section{Conclusion}

In summary, it has been shown that the negative capacitance of $\mathrm{nc}^{-\mathrm{TiO}_{2}} / \mathrm{P} 3 \mathrm{HT}$, heterojunction cells is dependent on the ambient condition. Furthermore. The capacitance values under forward bias was sum of depletion capacitance and diffusion capacitance. With increasing forward bias condition and/or under low frequency, the capacitance falling down to the negative part. That may be interpreted based on accumulating the minority charges carries a at interface between $\mathrm{P} 3 \mathrm{TH}$ and $\mathrm{nc}^{-\mathrm{TiO}_{2}}$ which plays an important role in displaying the negative capacitance (inductive behavior). On other hand, the negative capacitance was not observed in vacuum. This may be attributed to the absence of oxygen which affect on the conductivity of materials used in our solar cells. Finally, more work should be done to understand the properties of interfaces between $\mathrm{P} 3 \mathrm{HT}$ and $\mathrm{nc}-\mathrm{TiO}_{2}$ with a dye layer between them as function of ambient condition and appearance of negative capacitance negative capacitance.

\section{ACKNOWLEDGEMENT}

The researchers thank the Prof Martin Taylor (Bangor University) for undertaking the $\mathrm{AC}$ measurements.

\section{REFERENCES}

Al-Dmour, H. and D.M. Taylor, 2009. Revisiting the Origin of open circuit voltage in $\mathrm{nc}^{-\mathrm{TiO}_{2} / \text { polymer }}$ heterojunction. Solar Cells, Applied Phys. Lett., 94: 223309-223312. DOI: 10.1063/1.3153122

Al-Dmour, H. and D.M. Taylor, 2011. Small-signal response of nanocrystalline-titanum dioxide/poly(3hexylthiophene) heterojunction solar cell. Thin Soild Film, 519: 8135-8138. DOI: $10.1016 /$ j.tsf.2011.06.009

Arsian, E., Y. Safak, S. Altindal, K. Ozugr and E. Ozba, 2010. Temperature dependent negative capacitance behavior in (Ni/Au)/AlGaN/AlN/GaN) heterostructures. J. Non-Crystalline Solids, 356: 1006-1011. DOI: 10.1016/j.jnoncrysol.2010.01.024

El-Kamel, F., P. Gonon, F. Jomni and B. Yangui, 2008. Observation of negative capacitances in metalinsulatormetal devices based on a-BaTiO ${ }_{3}: \mathrm{H}$. Applied Phys. Lett., 93: 042904-042904.

DOI: 10.1063/1.2966352

Fan, Q., B. McQuillin, D. Bradley, S. Whitelegg and A. Seddon, 2001. A solid state solar cell using sol-gel processed material and a polymer. Chem. Phys. Lett., 347: 325-330.

DOI: 10.1016/S0009-2614(01)01003-X 
Gebeyehu, A., J. Brabec, F. Padinger, T. Fromherza and S. Spiekermann et al., 2001. Solid state dyesensitized $\mathrm{TiO}_{2}$ solar cells with poly(3octylthiophene) as hole transport layer. Synthetic Metals, 121: 1549-1552.

DOI: $10.1016 / \mathrm{S} 0379-6779(00) 01239-\mathrm{X}$

Itoj, E. and S. Nakagoshi, 2014. Impedance analysis of the multilayered organic solar cells with and without hole buffer layer. Japanese J. Applied Phys.; 53: 1-6. DOI: 10.7567/JJAP.53.04ER15

Jimrgensen, M., K. Norrman and F. Kerbs, 2008. Stability/degradation of polymer solar cells. Solar Energy Materials Solar Cells, 92: 324-714. DOI: 10.1016/j.solmat.2008.01.005

Lindmayer, J. and C. Wringle, 1966. Fundamentals of Semiconductor Devices. 1st Edn., Van Nostrand Reinhold, New York.

Meijer, E., A. Mangnus, B. Huisman, G. Hooft and D. Deleeuw et al., 2004. Photoimpedance spectroscopy of poly(3-hexyl thiophene) metalinsulator-semiconductor diode. Synthetic Metal. DOI: 10.1016/j.synthmet.2003.07.006

Rahid, M., A. Yusuf, M. ALHumayun, A. ALKhateeb and S. Tamaki, 2013. Stability analysis of solar cell characteristics above room temperature using indium nitride based quantum. Am. J. Applied Sci., 10: $1345-1350$. DOI: 10.3844/ajassp.2013.1345.1350

Sero, I., B. Germa, P. Boix, M. Vazquesb and J. Bisquert, 2009. Impedance spectroscopy characterisation of highly efficient silicon solar cells under different light illumination intensities. Energy Environm. Sci., 2: 678-686.

DOI: $10.1039 / \mathrm{b} 812468 \mathrm{j}$
Stallinga, P., H. Gomes, M. Murgia and K. Mullen, 2002. Interface state mapping in a Schottky barrier of the organic semiconductor terrylene. Organic Electronics, 3: 43-53.

DOI: $10.1016 / \mathrm{S} 1566-1199(02) 00024-1$

Taylor, D.M., H. Gomes, A. E Underhill, S. Edge and P.I. Clemenson, 1991. Effect of oxygen on the electrical characteristics of field effect transistors formed from electrochemically deposited films of poly(3 methylthiophene). J. Phys. D: Applied Phys., 24: 2032-2038. DOI: $10.1088 / 0022-3727 / 24 / 11 / 019$

Tsai, M., P. Chang, C. Liu and W.K. Lo, 2006. Shortdiode like diffusion capacitance of organic light emission devices. Thin Solid Film, 498: 244248. DOI: 10.1016/j.tsf.2005.07.104

Zaki, T., R. Rцde, F. Letzkus, H. Richter and U. Zshieschang et al., 2013. AC characterization of organic thin-film transistors with asymmetric gateto-source and gate-to-drain overlaps. Organic Electronic, 14: 1318-1322.

DOI: $10.1016 /$ j.orgel.2013.02.014

Zang, H ., Y. Hsiao and B. Hu, 2014. Surface-charge accumulation effects on open-circuit voltage in organic solar cells based on photoinduced impedance analysis. Phys. Chem. Chem. Phys., 16: 4971-4976. DOI: 10.1016/j.orgel.2013.02.014

Zhu, C., L. Feng, C. Wang, H. Cong and G. Zhang et al., 2009. Negative capacitance in lightemitting devices. Solid State Electronics, 53: 324-328. DOI: 10.1016/j.cplett.2006.02.060 